\title{
PRIVACY AND THE COMMUNITARIAN SELF
}

\author{
BY \\ BENJAMIN MOORE
}

A thesis

submitted to the Victoria University of Wellington

in fulfilment of the requirements for the degree of

Master of Arts

Victoria University of Wellington

2018 


\section{Table of Contents}

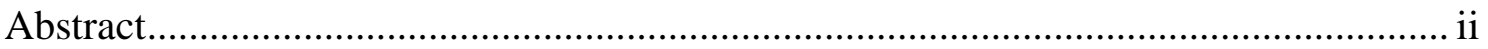

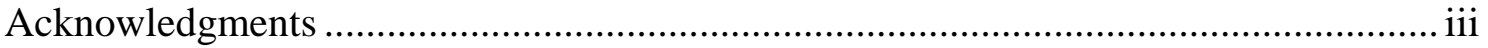

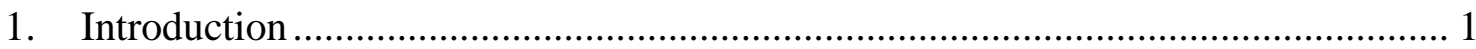

1a. A Preliminary Definition of Informational Privacy …...................................... 2

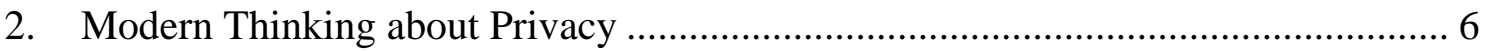

2a. The Tradition of Liberal-individualism .......................................................... 6

2b. Responding to a more Complex Society: Social Accounts of Privacy .............. 9

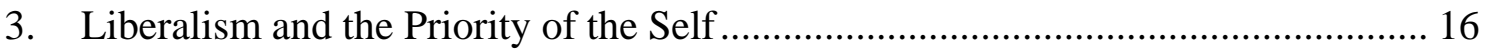

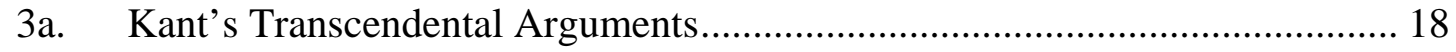

3b. Liberalism and Privacy .............................................................................. 27

4. Privacy and the Communitarian Self .................................................................... 29

4a. Personal Information and the Problem of Possession...................................... 29

4b. Characters, Narratives, and Traditions............................................................. 38

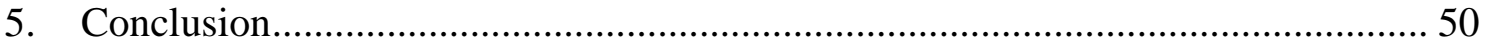

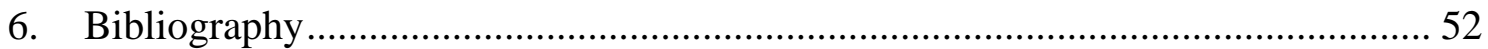




\begin{abstract}
Contemporary philosophical debates about privacy turn on important questions regarding selfhood. Minimally, someone who endorses the possibility of informational privacy is committed to the idea that there are 'selves' or 'persons,' and that it is possible to decide what information relates to them and how. I argue that most popular accounts of privacy rely on a liberal conception of the self. In the Kantian tradition, persons are characterised as 'transcendental subjects,' always partly prior to, and unencumbered by, their particular circumstances. Communitarians argue, however, that the liberal notion of the self offers only a partial account of personhood. It is not possible to reason as a transcendental subject because, in various ways, our sense of self is defined by circumstance. Our connections to various communities - such as a family, religion, or state - as well as the shared representations and meanings we rely on to gain self-knowledge, are indispensable parts of what it is be a person. Drawing on the work of Michael Sandel, Charles Taylor, and Alisdair MacIntyre, I argue that to properly account for our want of privacy and its moral significance, we must look to the complex relationships between a person, their personal information, and the communities they inhabit.
\end{abstract}




\section{ACKNOWLEDGMENTS}

I would like to thank my supervisor, Professor Edwin Mares of the School of History, Philosophy, and International Relations at Victoria University of Wellington, for invaluable guidance and reassurance. Thanks also to Jane and Joshua, for reading, reading, and reading some more. 


\section{INTRODUCTION}

'Civilization is the progress toward a society of privacy. The savage's whole existence is public, ruled by the laws of his tribe. Civilization is the process of setting man free from men.' ${ }^{1}$

- Ayn Rand, The Fountainhead.

Never has so much personal information been collected, analysed, and stored; so too our privacy has never seemed so threatened. Philosophers have generally lamented the decline of privacy, yet they lack much consensus about what privacy is and why it is valuable. This confusion has left philosophers unable to articulate with any clarity the moral and metaphysical problems privacy raises and how they might be settled. Though many arguments have been offered in the last half-century, little progress seems to have been made.

I am concerned with a kind of individualism dominant in philosophical accounts of privacy. It is easy to think privacy is about the interests of a single person against the collective, but this narrow view is, I will argue, holding privacy debates back. At the heart of this individualism is a view of that self that originates in liberalism. In the Kantian tradition, persons are characterised as 'transcendental subjects,' always partly prior to, and unencumbered by, their particular circumstances. Drawing on the insights of communitarian philosophers, I argue that old problems for the liberal view of the self gain new pertinence in the case of privacy. Though it may seem natural to think about privacy in individualistic terms, this fails to properly account for the complex relationships between a person, their information, and their community.

I begin in section 1 by distinguishing informational privacy from other related terms. In section 2, I offer a short history of the contemporary concept of privacy. Beginning with early legal defences from the turn of the twentieth-century, I trace the dominance of a kind of liberal individualism, one that pervades popular accounts of privacy through to

\footnotetext{
${ }^{1}$ Ayn Rand, The Fountainhead (Indeanapolis, IN: Bobbs-Merrill, 1943), 715.
} 
our own decade. Noting the increasingly information-centric nature of our societies, I then reflect on how a fledgling trend toward 'social accounts' of privacy, placing my work firmly to this task. Section 3 examines the roots of liberalism and, in particular, the view of the self that it requires. For this task I consider the key ethical insights of Immanuel Kant, both for their influence on modern liberalism and as representative of liberalism's main tenants. This sets up the $3^{\text {rd }}$ and final section, which presents the work of three communitarian philosophers: Michael Sandel, Charles Taylor, and Alasdair Macintyre. Together, these arguments provide strong grounds for rejecting the liberal view of the self, endorsing instead a view of the self that places equal emphasis on aspects of our connectedness, as well as our distinctness, as determining personal identity.

By exposing the assumptions of much philosophical thinking about privacy, I hope to draw attention to questions of personhood that must be engaged with if we are to make progress in debates about privacy. Only by appreciating the intricate relations between a person, their information, and their community, can we begin to develop a convincing account privacy and its moral and metaphysical significance.

\section{1a. A PRELIMINARY DEFINITION OF INFORMATIONAL PRIVACY}

The term 'privacy' is used so variably it is necessary to clarify my intended meaning at the outset. Ensuring this is done without bias is crucial, since a major task of my thesis is to argue that many theories of privacy need revision. But before a more thorough examination of specific theories of privacy can begin, we must first adopt a working definition of privacy. This needs to be both narrow enough to exclude those things I will not engage with, yet wide enough to allow an open-minded approach to those things I will consider. As a first attempt, I can say that I am concerned here with what is best described as informational privacy (though after this section it will be referred to simply as 'privacy' for the sake of brevity). Essentially, this is our ability to control information about ourselves, where 'information' is taken in an ordinary, everyday sense. There are meaningful facts that relate to us in personally identifiable ways, and having privacy is to be able to control who has access to this information. 
Luciano Floridi's ontological interpretation of privacy captures this notion excellently, and I will adopt his definition of privacy as a preliminary one. He defines informational privacy as a 'function of ontological friction.' 2 This notion is purposefully abstract, since it needs to capture the various ways that control over information can be achieved. He offers the following simple illustration:

'Imagine a model of a limited (region of the) infoshpere, represented by four students (our set of interactive, informational agents) living in the same house (our limited environment). Intuitively, given a certain amount of available information,...the larger the informational gap among the agents, the less they know about each other, the more private their lives can be. ${ }^{3}$

The 'infosphere' is some set of information. It can, if we wish, be defined as all the information that actually exists; a set containing all and every subset of the information in the universe. In most cases, however, it is more useful to deal with only a limited subset of this total, in this case all the personal information possibly available about the students. These students constitute informational agents - they can both produce information and capture it, as well as manipulate the environment in ways that affect how easily information can move through it. Within this particular environment (the house), various things prevent the students from knowing personal information about each other. They might, for instance, each have their own rooms and choose to close their doors. These kinds of factors create what Floridi calls ‘ontological friction': features of the ontology of the infosphere that impede the epistemic accessibility of information. ${ }^{4}$ This friction allows each student to maintain an informational gap from their housemates, because they each have access to information about themselves that the others do not.

Our capacity to control access to personal information depends on many factors. Facts about our nature play a primary role: our thoughts and sentiments cannot be known unless

\footnotetext{
${ }^{2}$ Luciano Floridi, “The Ontological Interpretation of Informational Privacy,” Ethics and Information Technology 7, no. 4 (2005): 186, doi:10.1007/s10676-006-0001-7.

${ }^{3}$ Ibid.

${ }^{4}$ Ibid.
} 
articulated, a restriction providing perhaps the most immediate form of informational privacy. Our status as agents capable of direct action also determines our ability to achieve informational privacy, such as when we hide our diaries or speak in a whisper. Floridi's definition does not discriminate between these and the many other conceivable ways control over personal information might be achieved. Informational privacy is simply ' $a$ function of restriction on the accessibility of information in the infosphere. ${ }^{5}$ There are many ways the flow of personal information might be impeded, and this is the essential basis and operation of informational privacy.

The beauty of Floridi's interpretation of privacy is its flexibility. First, he does not define the ways ontological friction might occur, but instead focuses on its outcome: that the epistemic accessibility of information is made either more or less difficult. This makes sense, given the multitude of ways the accessibility of information might be altered. It also future-proofs it against new, currently farfetched ways that might one day provide access to previously restricted areas of the infosphere; for example, the development of neurotechnology capable of reading thoughts in detail. Since the effects of such technology could be cached-out in terms of ontological friction, no revision of the essential doctrine would be required. More importantly for my thesis, Floridi's definition of informational privacy is morally neutral. It describes ways one's degree of informational privacy might be altered, but not whether this would be good or bad. Floridi does, in fact, have strong beliefs about the moral implications of privacy. ${ }^{6}$ Still, his ontological interpretation of privacy is separable from this aspect of his work, and is flexible and morally neutral as required for my purposes. This is partly due to the schematic notion of 'informational agent' Floridi uses. Indeed, he notes that agents 'need not be persons, they can be organisations, for example, or artificial constructs, or hybrid syntheses. ${ }^{7}$ This ambiguity means that, when talking about persons, the ontological interpretation is not committed to any particular theory of personhood. As far as they are

\footnotetext{
${ }^{5}$ Ibid., 187, emphasis in original.

${ }^{6}$ See for instance: Luciano Floridi, “On Human Dignity as a Foundation for the Right to Privacy,” Philosophy and Technology 29, no. 4 (2016): 307-12, doi:10.1007/s13347-016-0220-8.

${ }^{7}$ Luciano Floridi, “Four Challenges for a Theory of Informational Privacy,” Ethics and Information Technology 8, no. 3 (2006): 115, doi:10.1007/s10676-006-9121-3.
} 
an informational agent, a person can be defined anyway you please. Despite its generality, the ontological interpretation of privacy says enough to distinguish informational privacy from two related forms of personal control and autonomy. This is the real benefit of adopting it here, as my thesis is not concerned with either of these latter notions. First, informational privacy does not directly involve the physical self. We certainly have an interest in controlling what is done to our bodies, but this is not included under the concept of informational privacy. There are interesting cases of intersection, where the existence of information about our bodies, such as images or physical details, run together issues of informational privacy and bodily autonomy. For now, it is enough to point out that a person's right to control information about themselves should not be conflated with their right to control their body, since information is distinctly non-physical.

Privacy can also be taken to include a person's ability to make decisions free from state or social interference, particularly in legal contexts. ${ }^{8}$ Informational privacy may aid in free decision making, but the concept of informational privacy itself is only about having control over information, not what follows from this control. Privacy allows people to do many things they might not otherwise do, and some of these things may be beneficial or desirable. Still, having informational privacy is simply to have the ability to control information about oneself. With these distinctions in mind, we can turn to consider specific accounts of privacy, its moral and metaphysical dimensions, so as to clarify those aspects of current privacy debates I think mistaken.

\footnotetext{
${ }^{8}$ Oliver Diggelmann and Maria Nicole Cleis, “How the Right to Privacy Became a Human Right,” Human Rights Law Review 14, no. 3 (2014): 442, doi:10.1093/hrlr/ngu014.
} 


\section{MODERN THINKING ABOUT PRIVACY}

In this section, I identify two broad approaches to privacy that have been influential in philosophical and legal thinking of the last century, with the aim of making explicit the kind of individualism I think problematic. To begin, I examine the origins of modern thinking about privacy. These early thinkers established the view that privacy is an essentially individual interest, consisting in our 'right to be left alone.' This foundation established a dominant liberal individualism in philosophical thinking about privacy that lasted well into the twentieth-century. Next, I identify a shift in philosophical thinking that started around the 1970s. Philosophers frustrated with the limitations of old liberal arguments for privacy began investigating the social aspects of privacy in earnest. In these arguments I see a stronger, more discursive study of privacy, much better suited to explain the worries that modern technology presents for societies and citizens.

\section{2a. THE TRADITION OF LIBERAL-INDIVIDUALISM}

Modern legal thinking about privacy began with an influential 1890 Harvard Law Review article by Samuel Warren and Louis Brandeis. ${ }^{9}$ They argued that, though often analogous to property rights, the right to privacy protected a distinct interest that deserved legal protection. Unlike protections afforded to published works, the desire for privacy does not depend on the potential for monetary or artistic profit. Rather, the concealment of thoughts, sentiments, and emotions was required, above considerations of intellectual property, by our general right to be 'left alone'. Establishing a legal concept of privacy would, they thought, help to protect our right to an 'inviolate personality. ${ }^{10}$ Warren and Brandis's article inspired the creation of privacy law in the United States; their conception of the right to privacy adopted in some number torts that form the basis of nearly all states’ privacy laws today. ${ }^{11}$

\footnotetext{
9 Samuel D Warren and Louis D Brandeis, “The Right to Privacy,” Harvard Law Review 4, no. 5 (1890): 193-220, doi:10.1525/sp.2007.54.1.23.

10 Ibid., 205.

${ }^{11}$ Daniel Solove, Understanding Privacy (Cambridge, MA.: Harvard University Press, 2008), 16.
} 
Alan F. Westin would later refine Warren and Brandis’s doctrine in his famous 1967 book, Privacy and Freedom. ${ }^{12}$ Drawing on studies of various insights, including some from the animal kingdom, postulations about the development of early societies, and the more recent influence of America’s exceptional political individualism, he concluded that everyone, at different times and under different circumstances, is drawn by competing desires for solitude and companionship, intimacy and intercourse. ${ }^{13}$ Westin identified four central functions of privacy in helping us balance these legitimate interests: it allowed the maintenance of solitude, intimacy, anonymity, and reserve ${ }^{14}$ (the 'creation of a psychological barrier against unwanted intrusion' ${ }^{15}$ ). He considered the question of just how much of each form of privacy is right to be a largely individual choice, stating forcefully that 'any truly free society must recognise the right of the individual to decide for himself, with only extraordinary exceptions in the interests of society, when and on what terms his act should be revealed to the general public. ${ }^{\text {'16 }}$

With their focus on how privacy serves the interests of each individual, these early thinkers conceived privacy in fairly standard liberal, rights-based terms. This was a successful framework, one that still exerted influenced on philosophers decades later. Some twenty-years after Westin's book, Richard Hixson stated that privacy 'tries to distinguish between the individual and collective,' being a concept 'based upon respect for the individual and individualism ${ }^{17}$ - an unadulterated formulation of Westin's thesis he should have happily endorsed.

Even philosophers who were later sceptical of the right to privacy adopted the terms of liberal individualism in their arguments without much alteration. In a well-known 1975 paper, Judith Jarvis Thompson lamented how ill-defined the concept was. Proposing to

\footnotetext{
${ }^{12}$ Alan Westin, Privacy and Freedom (New York, NY: Atheneum, 1967).

${ }^{13}$ Ibid., 42.

${ }^{14}$ Ibid., 32-33.

15 Ibid., 32.

16 Ibid., 42.

${ }^{17}$ Richard F Hixson, Privacy in Public Society: Human Rights in Conflict (New York, NY: Oxford University Press, 1987), 212.
} 
examine several seemingly uncontroversial cases where someone's privacy would be violated, she sought to determine what, if anything, they had in common. ${ }^{18}$ Having considered circumstances both bane and far-fetched, failing to find any unifying wrong that was present in each, she offered a simplifying hypothesis: what we call the right to privacy 'is itself a cluster of rights, and...is not a distinct cluster of rights but itself intersects with the cluster of rights which the right over person consists in and also with the cluster of rights of which owning property consists in.' ${ }^{19}$ Though ultimately deflationary, Thompson searched for the meaning and value of privacy for the isolated individual, an inquiry who’s terms were set by much earlier thinkers.

Contemporary responses to Thompson's article further demonstrate the dominance of liberal individualism in privacy debates of the time. Thomas Scanlon insisted that privacy protects our 'broader interests in having a zone...in which we can carry out our activities without the necessity of being continually on alert for possible observers, listeners, etc. ${ }^{20}$ Even more forcefully, Jefferey H. Reiman described privacy as 'a social ritual by means of which an individual's moral title to his existence is communicated. ${ }^{21}$

As a final example, we may take the more recent work of Andrei Marmor to show that liberal individualism is still central in philosophical thinking about privacy. He contends that the main interest we have in privacy is 'having a reasonable measure of control over ways in which we present ourselves to others and the ability to present different aspects of ourselves, and what is ours, to different people. ${ }^{22}$ Among other things, this desire for control over what one reveals about themselves pertains 'to people's willingness to subject various aspects of themselves to social scrutiny. ${ }^{23}$ Here again the individual is the centre of concern in an account privacy. Marmor's focus on a person's desire to

\footnotetext{
18 Judith Jarvis Thompson, “The Right to Privacy,” Philosophy \& Public Affairs 4, no. 4 (1975): 295-96.

19 Ibid., 306.

20 Thomas Scanlon, “Thompson on Privacy,” Philosophy \& Public Affairs 4, no. 4 (1975): 317.

21 Jeffrey H. Reiman, "Privacy, Intimacy, and Personhood,” Philosophy \& Public Affairs 6, no. 1 (1976): 39, http://ezproxy.library.nyu.edu:2105/stable/2265060.

22 Andrei Marmor, “What Is the Right to Privacy?,” Philosophy \& Public Affairs 43, no. 1 (2015): 7.

${ }^{23}$ Ibid., 9.
} 
control information about themselves, in respect of the potential harms of their community, follows lines of argument established by earlier liberal philosophers.

These thinkers, from Warren and Brandis at the turn of the last century to Marmor in our own decade, represent a long-standing tradition of liberal individualism in AngloAmerican debates about privacy. Their shared focus on both individual rights and individual control are themes which dominated legal and philosophical discourse through to at least the 1980s. ${ }^{24}$ Theorists following this tradition have argued privacy is some kind of protection owed to individuals, usually in tension with the interests of the community. When cast as an issue of individual rights, what is usually perceived to be at stake is some degree of individual autonomy. Privacy, it is often maintained, is a necessary protection owed to each person against unjust interference by others. American legal scholar Thomas Emerson summed up this view expertly, saying privacy is 'based upon premises of individualism. That the society exists to promote the worth and dignity of the individual. ${ }^{25}$

\section{2b. ReSPONDING TO A MORE COMPLEX SOCIETY: SOCIAL ACCOUNTS OF}

\section{PRIVACY}

Though liberal, rights-based accounts of privacy have lasted admirably well, since the 1980s an increasing number of theorists have expressed frustration at their limitations. These developments have accompanied the rapid introduction of new technologies that make possible methods and volumes of information gathering, storage, and processing never before imagined. This has created new privacy issues early thinkers could not have anticipated. With the maturing of the internet, the transition into the twenty-first century has been one of particularly exceptional change. Almost nothing has been untouched by an incessant move toward connectedness. Our personal, professional, and political lives have all increasingly moved online, and for those in developed countries almost

\footnotetext{
${ }^{24}$ Priscilla M. Regan, "Privacy and the Common Good: Revisited,” in Social Dimsensions of Privacy, ed. Beate Roessler and Dorota Mokrosinska (Cambridge: Cambridge University Press, 2015), 53.

${ }^{25}$ Thomas I Emerson, The System of Freedom of Expression (New York, NY: Random House, 1970), 545.
} 
everything we do - from shopping and banking, to learning and finding love - is done with the use of information technology.

These changes have seen the amount of information humans gather increase at a staggering rate: in year 2009, the total volume of data stored in the world was 800,000 petabytes, by 2020 it is expected to reach 35 zettabytes $^{26}$ - a more than forty-three-fold increase. Not only has this made our social lives much larger in scale, but they are also now much more complex. The majority of information is of course collected by large companies and governments. It is now generally accepted, however, that these entities are not just isolated enterprises, but form parts of larger 'sociotechnical' systems. ${ }^{27}$ This phrase acknowledges that information systems cannot be understood merely by the hardware and software of their machine components. As well as technical artefacts, they are the sum of interdependent systems comprised of (at least) social actors, defined and undefined rules and customs, and situated meanings. ${ }^{28}$ Awareness of the complexity of new information technologies has also brought an increased awareness of the limitations of an overly individualistic approach to privacy. Pieter Vermaas notes that 'one of the features of sociotechnical systems is that they are less predictable than traditional technical artefacts.' 29 This unpredictability, accompanied by the pervasiveness of information gathering, has left classical-liberal accounts of privacy poorly equipped to diagnose the multitude of privacy concerns raised by modern life.

One of the primary complaints has been that characterising privacy as primarily in the interest of individuals leaves it vulnerable to being undervalued. Priscilla Regan notes that, particularly post-9/11, the necessity of protecting national security has widely legitimised the expansion of surveillance and information gathering to both governments

\footnotetext{
${ }^{26}$ Hrushikesha Mohanty, “Big Data: An Introduction,” in Big Data, ed. Hrushikesha Mohanty, Prachet Bhuyan, and Deepak Chenthati, vol. 11, Studies in Big Data (New Delhi: Springer India, 2015), 3, doi:10.1007/978-81-322-2494-5. ${ }^{27}$ Deborah G Johson and Priscilla M Regan, eds., Transparency and Surveillance as Sociotechnical Accountability: A House of Mirrors (New York, NY: Routledge, 2014).

${ }^{28}$ Regan, "Privacy and the Common Good: Revisited,” 51.

${ }^{29}$ Pieter Vermaas et al., A Philosophy of Technology: From Technical Artefacts to Sociotechnical Systems, Synthesis Lectures on Engineers, Technology and Society, vol. 6, 2011, 81, doi:10.2200/S00321ED1V01Y201012ETS014.
} 
and citizens. ${ }^{30}$ Issues of security are often believed to trump the comparably trivial interest an individual has in securing their personal information. But the harms of a loss of privacy on social goods, such as freedom, creativity, and public engagement, are regularly ignored in this balance. Oddly, as Daniel Solove notes, the interests aligned against privacy - including national security - are often cached out in larger social terms. ${ }^{31}$ It is no wonder that, without an understanding of its broader social aspects, privacy seems an extravagant protection when weighted against the security of the many.

The other main difficulty philosophers have had with liberal, rights-based accounts of privacy is that they are often imprecise about how it functions. This renders them ineffective as tools for assessing specific cases of privacy violations. Solove surveys a number of ways privacy might be thought to protect the individual, finding each objectionable for being either too broad or too narrow, or overly vague. ${ }^{32}$ Whether privacy is said to consist in our right to be let alone, to maintain limited access to ourselves, to establish secrets, or merely to exert control of our personal information, much more needs to be said about what, exactly, constitutes personal information. Many theorists leave this question of what constitutes personal information, or which matters underpin privacy concerns, unanswered, often assuming them to be trivial. But without further argument, Solove insists that we need not accept the claim that information is inherently public or private. ${ }^{33}$ Factors relating to circumstance are often of central importance in deciding whether information is deemed worthy of protection. Without an appreciation for the dynamics of circumstance on how important we perceive information to be, many liberal theories of privacy fail to provide a method for deciding if a specific case should count as a privacy violation or not.

Finally, feminist theorists have argued that liberal accounts of privacy ignore its potential to harm the interests of woman, particularly in the home. Catherine MacKinnon has

\footnotetext{
${ }^{30}$ Regan, "Privacy and the Common Good: Revisited,” 52.

${ }^{31}$ Solove, Understanding Privacy, 89.

32 Ibid., chap. 2.

${ }^{33}$ Daniel J Solove, “The Meaning and Value of Privacy,” in Social Dimsensions of Privacy, ed. Beate Roessler and Dorota Mokrosinska (Cambridge: Cambridge University Press, 2015), 75.
} 
insisted that privacy protects another domain where woman are deprived of power, and that feminists must confront 'the fact that woman have no privacy to lose or to guarantee. ${ }^{34}$ She makes two related points in light of this. First, woman lack privacy because they are violable and violated, lacking autonomy and self-control. Second, privacy is usually detrimental to them, providing a place for men to subjugate them. For example, protections of one's home, sometimes thought to be privacy rights, have been used to shield abuses of woman and children under the pretence that they are 'private' issues, rather than political or social ones. ${ }^{35}$ Other theorists have argued that there are contexts where privacy genuinely serves woman, but take MacKinnon's point to warn about that accounts of privacy must engage in its political and social ramifications. Judith DeCew, for one, maintains hopeful that feminists can endorse a theory of privacy which 'embraces the importance of privacy, yet allows privacy invasions when taking account of social relationships between men and woman within the context of various areas of everyday life.' 36

Because of these frustrations, the project of broadening our understanding of privacy beyond its meaning and value of the individual has gained increasing attention for some time. As early as the 1970s, small groups of philosophers were trying to grapple with how to expand liberal accounts of privacy to include social aspects. For instance, in response to Thompson's 1975 paper mentioned earlier, James Rachels argued that 'there is a close connection between our ability to control who has access to us and to information about us, and our ability to create and maintain different sorts of social relationships with different people. ${ }^{37}$ Even here, though, the importance of privacy for the individual in maintaining relationships is Rachels' primary focus. Accounts that considered the uniquely social aspects of privacy became mainstream only much later.

\footnotetext{
${ }^{34}$ Catharine MacKinnon, Toward a Feminist Theory of the State (Cambridge, MA.: Harvard University Press, 1989), 191.

35 Judith Wagner DeCew, “The Feminist Critique of Privacy,” in Social Dimsensions of Privacy, ed. Beate Roessler and Dorota Mokrosinska (Cambridge: Cambridge University Press, 2015), 89.

${ }^{36}$ Ibid., 101.

37 J Rachels, “Why Privacy Is Important,” Philosophy \& Public Affairs 4, no. 4 (1975): 326, https://www.jstor.org/stable/2265077.
} 
The identification of social accounts of privacy, in contrast to their liberal, rights-based predecessors, is admittedly more of a theoretical convenience than clear-cut dichotomy. Though there are absolutist examples of each, most theories of privacy fit somewhere on a spectrum, having greater or lesser focus on the rights and interests of the individual and the social aspects of privacy respectively. But, the philosophical literature does portray a clear trend of increasing attention to the social aspects of privacy, as well as the diminishing popularity of those views that represent an extremely traditional, liberal approach. And in the last decade new social accounts have come to the forefront of philosophical work on privacy. Priscilla Regan has noted that '[a]mong legal scholars, philosophers and social scientists interested in privacy, there is an unmistakable sense that situating privacy as a social value is appropriate, intellectually defensible and vital. ${ }^{38}$

Some have set about this task by arguing that when balancing the interest of the individual and society, restraints on privacy should be subject to checks and balances which maximise the interests of the individual as far as possible. For instance, Amitai Etzioni acknowledges that nations face several fully legitimate, competing claims regarding privacy and security, and that these can be neither mutually maximised nor fully reconciled. ${ }^{39}$ But rather than accepting that privacy or security must trump, he insists that the main task of governments is to strike a balance. This depends largely on circumstances: governments may only restrict privacy when there exists a real threat to security, and they must do this with the greatest level of restraint compatible with a reasonable level of security. He contrasts his analysis with that of liberal theorists who emphasize individual rights and autonomy over social considerations, while also distancing himself from those at the other extreme, who 'privilege the common good $a$ priori, and pay mind to rights mainly to the extent that they serve the rulers' aims. ${ }^{40}$

Despite its novel aspects, Etzioni's work does not advance thinking about the social aspects very far. His insistence that privacy must be balanced against security accounts

\footnotetext{
38 Regan, “Privacy and the Common Good: Revisited,” 55.

${ }^{39}$ Amitai Etzioni, Privacy in a Cybver Age: Policy and Practice (New York, NY: Palgrave Macmillan, 2015), 101.

40 Ibid., 101-3.
} 
for the interests of both the individual and the community, but fails to integrate them satisfactorily. ${ }^{41}$ To him the two are in irreconcilable conflict. The task of philosophers working on the social aspects of privacy is, he thinks, to explain how we can 'balance individual rights with social responsibilities, and individuality with community. ${ }^{42}$ This still pits the interests of the individual against those of their community, doing little to dissolve the conflict at the heart of more standard theories of privacy.

Philosophers like Daniel Solove have done more to dispel the perceived tensions between individual and social interests in privacy debates. He argues that the value of privacy should be assessed on the basis of its contributions to society, and that protecting individual privacy 'need not be at society's expense - in fact, the value of safeguarding people's privacy should be justified by its social benefits. ${ }^{43}$ Amongst the plurality of goods Solove thinks privacy protects, one is the promotion of strong protections for the individual. This is not done, however, because individual rights trumpet social interests, but because society has well established norms and practices regarding the protection of the individual. Privacy is thus not an external constraint on society, but an internal function of a well-ordered community. ${ }^{44}$

Perhaps the best known philosophical work in this area is that of Priscilla Regan. Lamenting the legislative weaknesses of privacy protections, which Regan blames on the pervading liberal, individualistic focus of privacy debate ${ }^{45}$, she identifies three unquietly social aspects of privacy and explains how these secure goods not just for the individual, but for society at large. Citing empirical evidence for the widespread belief that privacy is important and near universal conceptions about norms and standards related to it, she argues that it is widely perceived as an important function of a good society, not just a

\footnotetext{
${ }^{41}$ A similar point is made by: Solove, Understanding Privacy, 90-91.

${ }^{42}$ Amitai Etzioni, The Limits of Privacy (New York, NY: Basic Books, 2008), 198.

43 Solove, Understanding Privacy, 91.

${ }^{44}$ Solove, “The Meaning and Value of Privacy,” 78-80.

45 Priscilla M. Regan, Legislating Privacy: Technology, Social Values, and Public Policy, Reissue Ed (Chapel Hill, NC: The University of North Carolina Press, 1995), 24.
} 
protection desired by individuals for their own sake. ${ }^{46}$ She also notes its role in securing social goods such as democracy ${ }^{47}$, and the fact that technological innovations make it is very difficult for any one individual to enjoy privacy without others enjoying a similar minimal level. ${ }^{48}$ These goods are, according to Regan, common, public, and collective values respectively.

The work of these philosophers portrays an increasingly broad understanding of privacy. Eschewing the strict individualism of previous thinkers, they are engaged in a conscious search for new arguments that will bolster the value afforded to privacy in modern political and social systems. A more discursive study of the importance and value of privacy is surely a good thing.

\footnotetext{
${ }^{46}$ Regan, “Privacy and the Common Good: Revisited,” 56.

47 Ibid., 60.

${ }^{48}$ Ibid., 62.
} 


\section{LIBERALISM AND THE PRIORITY OF THE SELF}

I hope in the following sections to suggest a way the project of integrating the full role of social circumstances into accounts of privacy might be taken further. To see how, we need to distinguish two areas of enquiry regarding privacy. First, there are moral questions. These include why privacy is morally significant, whether people have a right to it, and how privacy is to be balanced against competing interests. These and related problems are by far the most discussed aspects of privacy. Second, there are the epistemological and metaphysical questions privacy raises. Most obviously, these include how an individual must be constituted to have privacy in the first place, and what this says about persons and their relation to others. Reflecting on all the arguments we have considered for privacy, it is striking how little philosophers have addressed questions of the latter group.

The problem, I think, is that when writing about privacy many philosophers neglect a number of epistemological and metaphysical problems of personal identity that are intimately related to the stance they take on the moral status of privacy. But questions about the morality of privacy cannot be answered without making assumptions about these epistemological and metaphysical questions. Minimally, someone who endorses the possibility of informational privacy is committed to the idea that there are 'selves' or 'persons,' and that it is possible to decide what information relates to them and how. To claim there is personal information is therefore to endorse some kind of metaphysics of the self, even if it is a very thin one.

Most social accounts so far offered extend the classical liberal conception of privacy by claiming the interests and goods which it protects are, at least partly, the aggregate and intersecting goods and interests of many individuals. Some openly acknowledge this; Solove, for instance, says that his taxonomy of privacy 'starts with the individual, the primary subject of privacy concern. ${ }^{49}$ This addresses some of the deficiencies in liberal accounts of privacy and draws attention to important social aspects of the moral value of privacy. I want to suggest, however, that in addition to these aggregate social goods, the

\footnotetext{
${ }^{49}$ Solove, “The Meaning and Value of Privacy,” 77.
} 
community forms a fundamental part of the epistemological and metaphysical conditions of privacy for the individual.

Essentially, my claim will be that the relationships between an individual person, their information, and their community are not trivial, and that only by acknowledging this can we understand the truly social nature of privacy at the epistemological and metaphysical level. Talk of privacy as a right belonging to the isolated individual is problematic because the possibility of self-knowledge and definition personal information - what I consider to be me and what I think is my information - depends not only on my status as an individuated subject, but is determined also by the communities I am part of. Our concept of privacy therefore emerges, I will argue, from the complex social relations that determine what we consider ours and who we. This point is compatible with, and complimentary to, the task philosophers have set themselves of better understanding the social dimensions of privacy.

Something like this is gestured at by Janice Richardson, when she reflects on how the 'different meanings of privacy have affected the way we live and how we see ourselves. ${ }^{50}$ An example of this is that courts, particularly those in Europe, have in recent decades shifted their focus in privacy rulings from a focus solely on the individual by, for example, considering that harms done to relationships when information is disclosed. ${ }^{51}$ Though they 'do not express a detailed ontology in which self and other emerge through their daily habits and relations with others...they clearly view relationships as of central importance to producing "who we are". 52 This is compatible with the view I will develop: that to a certain extent relationships come first, and that a robust individuality (including the concept of privacy) depends on our relationship with others.

Showing this clearly requires much more argument. The path I suggest uses existing tools: the work already done by a loosely aligned group of philosophers know as

\footnotetext{
50 Janice Richardson, “The Changing Meaning of Privacy, Identity and Contemporary Feminist Philosophy,” Minds and Machines 21, no. 4 (2011): 530, doi:10.1007/s11023-011-9257-8.

${ }^{51}$ Ibid., 521-24.

${ }^{52}$ Ibid., 530.
} 
communitarians. Between them, they have developed various arguments for the deficiency of the liberal project in general, and the liberal conception of the self in particular. Their emphasis on the importance of community in our moral lives addresses many of the same shortcomings theorists attack in classical-liberal defences of privacy. In particular, it is their arguments for the epistemological and metaphysical basis of selfknowledge and personhood which I will focus on. My aim in engaging the work of communitarians is to two make two specific points. First, the negative claim that since the focus of liberal ethics - the identification of the rights and interests of individual sovereign subjects - is so radically unencumbered, it is unclear how we can use it to reason about personal information in a meaningful way. The kind of self-knowledge that a moral interest in privacy requires is not one that the detached moral subject would obviously be capable of. To be plausible regarding privacy, a liberal conception of the subject in relation to its personal information also needs to be provided. Relatedly, I will make the positive claim that we care about privacy only because we belong to groups of persons capable of interacting, and particular interactions are imbued with significance by what the information means in those communities. What I consider mine and about me depends, in large part, on the norms and customs of the communities I am part of. This suggests that approaches to privacy which include a more central role for one's social situation are much better equipped to deal with our motivations for privacy, and the importance we feel attaches to it.

\section{3a. KANT’S TRANSCENDENTAL ARGUMENTS}

The task ahead requires a few digressions before issues of privacy can be tackled headon. To understand the importance communitarian philosophers have placed on communities in shaping personal identity, it is necessary to first appreciate the motivations and commitments of liberal ethics, particularly in its conception of the self. The kind of liberalism we have found problematic in accounts of privacy is that which treats as primary the claims, interests, and rights of the individual in moral reasoning. I agree with Michael Sandel that the most liberal arguments of this kind are indebted to 
Immanuel Kant for their philosophical foundation. ${ }^{53}$ His arguments about the self - both epistemological and ethical in focus - are some of the most influential in the Western philosophy, and form the basis of much contemporary moral and political thought. Most importantly for the task at hand, they provide the motivation for much of the rights-based individualism that has dominated privacy debates for so long.

Now some liberal theorists have tried to liberate Kant's transcendental arguments from his ethical insights. Rawls' political philosophy is easily the most famous attempt at this. His ambition in A Theory of Justice ${ }^{54}$ was to 'present a natural procedural rendering of Kant's conception of the kingdom of ends, and of the notions of autonomy and the categorical imperative,' 55 with the hope that 'the underlying structure of Kant's doctrine [would be] detached from its metaphysical surroundings. ${ }^{56}$ For the task at hand, however, not much turns on the success of these sorts of Kantian-inspired projects. There are two reasons I have chosen to engage with Kant's original arguments here. First, the aspect of liberalism that concerns us is the view of the self that it requires, since, as we will see, this is what underlies the individualism that we found problematic in liberal accounts of privacy. Kant's arguments about the self will demonstrate the basis for the liberal's privileging of individual rights and interests perfectly well. This is the central supposed moral fact that liberal, rights-based ethics affirms, and to which communitarian's criticisms mainly confront. Though influential on modern debates, Rawls' political philosophy covers many more questions that will not be directly addressed here. There is also the more general point that, because of his historical precedence, Kant's arguments have had a substantial influence on the development of liberal political and ethical thinking. This influence means, I think, that his general points about the self capture the main commitments of most common liberal thinking, especially of the sort we are concerned with.

\footnotetext{
${ }^{53}$ Michael J Sandel, Liberalism and the Limits of Justice (Cambridge: Cambridge University Press, 1998), 1.

${ }^{54}$ John Rawls, A Theory of Justice (Oxford: Clarendon Press, 1972).

55 Ibid., 264.

${ }^{56}$ Ibid.
} 
Two of Kant's arguments regarding the self concern us here, each forming an indispensable part of his ethics. ${ }^{57}$ The first is an epistemological point about the basis of self-knowledge: his famous claim for the 'transcendental unity of apperception,' developed in the Critique of Pure Reason (1781) ${ }^{58}$. It is a fundamental and mutually supportive conclusion for a second practical argument advanced in the Groundwork for the Metaphysics of Morals (1785) ${ }^{59}$. There Kant presents his very special notion of freedom and autonomy, from which we will finally see the motivation for the liberal focus on the moral rights and interests of the individual.

Kant's epistemological argument for the transcendental unity of apperception is laid out in a section of the Critique entitled the Transcendental deduction of the pure concepts of understanding. ${ }^{60}$ A deduction, in Kant's use, is best thought of as process of abstraction. His method is to try to isolate the grounds a statement, proposition, or judgement, with the aim of revelling certain presuppositions that must be true because they are necessitated by certain seemingly indispensable features of our experience. They are transcendental arguments because they are meant to reveal truths which go beyond experience. James Scott Johnston nicely distinguishes a metaphysical deduction from a transcendental one. ${ }^{61}$ While a metaphysical deduction tries to isolate the metaphysical (or logical) ground of a statement, proposition, or judgement; a transcendental deduction aims at isolating the pure, a priori, and necessary reflective ground.

One of the judgements Kant considers in demonstration of the necessary unity of apperception is a very broad one. Indeed, it may be the broadest judgement we can make about any experience whatsoever. Though outwardly pedestrian, the epistemological and

\footnotetext{
${ }^{57}$ These two arguments are identified with a slightly different focus by: Sandel, Liberalism and the Limits of Justice, 7.

${ }^{58}$ Here I refer to: Immanuel Kant, The Critique of Pure Reason, trans. Paul Guyer and Allen W Wood (Cambridge: Cambridge University Press, 1998). Page references are usuaully to the original B edition. For the passages quoted, little difference appears from the A edition.

${ }^{59}$ Here I refer to: Immanuel Kant, The Moral Law: Groundwork for the Metaphysics of Morals, trans. H J Paton (London: Routledge, 2005).

${ }^{60}$ Kant, The Critique of Pure Reason, B129-69.

61 James Scott Johnston, Kant’s Philosophy: A Study for Educators (New York, NY: Bloomsbury, 2013), 42.
} 
(later) moral conclusions Kant draws from it are truly impressive. In summary the judgement is simply that, in order to experience the world as I do, it must be that all my disparate empirical intuitions are united in one subject of experience:

'The I think must be able to accompany all my representations; for otherwise something would be represented in me that could not be thought at all, which is as much to say that the representation would either be impossible or else at least would be nothing for me. ${ }^{, 62}$

Peter Strawson finds two related thoughts expressed in Kant's assessment of the I think. ${ }^{63}$ One is that intuitions must be brought under concepts before they can be experienced. To have a representation (or an experience of something) is to take raw (empirical) intuitions though the faculty of understanding. This point is central to Kant's overall metaphysics, but we can note it here parenthetically. What is of more interest is the relationship the I think suggests between consciousness and self-consciousness. It is the idea that if different experiences are to belong to a single consciousness, it must be possible for the subject of that consciousness to be aware of itself.

The conclusion that a subject of a single consciousness must be able to know of its identity from its experiences is major. It is intended in large part to answer the problem of how self-consciousness is possible on what might be called ordinary empirical grounds. Elsewhere Kant notes that:

'The consciousness of oneself in accordance with the determinations of our state in internal perceptions is merely empirical, forever variable; it can provide no standing or abiding self in this stream of inner appearances..., 64

\footnotetext{
${ }^{62}$ Kant, The Critique of Pure Reason, B133-134.

${ }^{63}$ Peter F Strawson, The Bounds of Sense: An Essay on Kant's Critique of Pure Reason (New York, NY: Routledge, 1966), 93.

${ }^{64}$ Kant, The Critique of Pure Reason, A107.
} 
This point is also raised in the Groundwork, ${ }^{65}$ and is the one of the main problems his argument for the necessary unity of apperception is meant to answer. Observing our inner sensations - being just the empirical intuitions we are subject to - revels only transitory and disconnected pieces of experience. As Kant notes slightly later, the problem is that 'the empirical consciousness that accompanies different representations is by itself dispersed and without relation to the identity of the subject, ${ }^{66}$ since on their own the empirical representations of consciousness do not form a persisting unity. Without a synthesising of these parts 'I would have as multicolored, diverse a self as I have representations of which I am conscious. ${ }^{67}$ As Peter Strawson points out, the problem is not really that these inner states are changeable; even if we had only steady states of inner sensations these would still not be states belonging to a single subject - they would not be mine or part of me. ${ }^{68}$ The $\mathbf{I}$ think bridges the gap between a numerically singular, persisting subject and its multitudinous, varying empirical intuitions, by showing that the act of empirical self-ascription requires a consciousness that is capable of knowing its own identity through empirical determinations, whether constant or changing.

Though Kant thinks a form of self-knowledge follows from the principle of the transcendental unity of apperception, it is of a particularly restricted kind. In a footnote he states that 'the I think expresses the act of determining my existence.' ${ }^{69}$ He remains uncommitted, however, on whether this act is a conscious one, noting that the thought that the representations given in intuition one and all belong to me means just that I 'unite them in a self-consciousness, or at least can unite them therein. ${ }^{70}$ And in considering the transcendental unity of apperception Kant concludes that 'I am conscious of myself not as I appear to myself, nor as I am in myself, but only that I am,' and so 'I therefore have no cognition of myself as I am, but only as I appear to myself., ${ }^{71}$

\footnotetext{
${ }^{65}$ Kant, The Moral Law: Groundwork for the Metaphysics of Morals, 133.

${ }^{66}$ Kant, The Critique of Pure Reason, B133.

${ }^{67}$ Ibid., B134.

${ }^{68}$ Strawson, The Bounds of Sense: An Essay on Kant's Critique of Pure Reason, 93-94.

${ }^{69}$ Kant, The Critique of Pure Reason, B157.

${ }^{70}$ Ibid., B133-34, my emphasis.

${ }^{71}$ Ibid., B157-58.
} 
Here Kant makes a distinction that is at the heart of his metaphysics: that between the worlds of phenomena and noumena. So far as I can consider an object, it is in one aspect only a phenomenon; only an appearance that is the result of my empirical intuitions. But, says Kant, by calling an object forward my understanding also inevitably 'forms for itself, apart from this aspect, another representation of an object in itself. ${ }^{72}$ This latter thought, that beside my knowledge of how an object appears to me, it might also be considered as it is in itself, refers to its noumenal existence. Our understanding, however, can have no knowledge of even the possibility of noumena, since all knowledge consists in operations of the understanding on sensible (empirical) intuition. It is important to appreciate this point. Kant does not claim that the I think shows anything beyond experience directly. In this he is in agreement with a more standardly empirical picture of perception and our knowledge of the world. But, he does argue that in order to explain the demonstrable unity of our consciousness we must assume that an aspect of us is extra-sensible, or beyond the world of empirical intuitions. Still, since all we directly perceive is the world of phenomena, we must still resign ourselves to knowing only about nature so far as empirical self-consciousness allows. I take the main achievement of Kant's argument to be a kind of gesture at the apparently transcendental truth that, beyond the phenomenon of empirical conscious, I must also assume that, given the necessity of the transcendental unity of apperception in producing my potential empirical self-consciousness, I am also part of a world beyond mere appearance.

With this epistemological point secure, we can turn to the second, practical argument that concerns us. Part of Kant's aim in the Groundwork is to develop an account of the transcendental subject, particularly as it relates to moral reasoning. First, Kant recounts the argument of the Critique just considered:

'[B]eyond this character of himself as a subject made up, as it is, of mere appearances he must suppose there to be something else which is its ground - namely his Ego as this may be constituted in itself.' 73

\footnotetext{
72 Ibid., B306-7.

${ }^{73}$ Kant, The Moral Law: Groundwork for the Metaphysics of Morals, 133.
} 
Again, the idea here is that since introspection into our inner sensations reveals only disjointed empirical intuitions, we must also assume that we are partly constituted by a transcendental nature. It must be supposed that there is a transcendental subject (which Kant here calls the 'Ego') that is 'back there' doing the synthesising of my representations, and which is antecedent to any particular experiences. This leads to an important distinction between two standpoints from which we might conceive ourselves. First, as far as I have 'mere perception and the capacity for receiving sensations, ${ }^{, 74} \mathrm{I}$ am an object of experience, and must count myself as belonging to the sensible world. Observing my body, for instance, revels a succession of sensible intuitions that I can consider. As a body, I am no different to other objects that I encounter in the sensible world. At the same time, as far as I grasp a manifold of representations as mine, I am aware of something that 'comes into consciousness not through affection of the sense, but immediately. ${ }^{75}$ This is the claim of the transcendental unity of apperception that Kant developed more fully in the Critique. When I consider myself in this way, I am the subject of experience, and in this capacity I must count myself as part of the intelligible world. Of this, however, Kant warns that I can 'know nothing further.'76

The discovery that I must understand myself as a subject as well as an object of experience further suggests two different ways of conceiving of myself in relation to my actions. ${ }^{77}$ First, as an object of experience, I belong to a world of sensibility and empirical representations. Here my actions are determined as much as the movements of all other objects, by the laws of nature and the regularities of cause and effect. My hands move, for instance, in accordance with these restrictions. As far as I can will something in accordance with my existence as part of the sensible world, my actions will still be determined by natural laws as much as everything else. But as a subject of experience, I inhabit a world beyond that of the sensible world. Here my will is independent of the laws of nature. It is only from the second standpoint that I can regard myself as autonomous,

\footnotetext{
${ }^{74}$ Ibid.

75 Ibid., 134.

${ }^{76}$ Ibid.

77 Ibid., 135.
} 
since 'to be independent of determination by causes in the sensible world...is to be free.' 78

The part of us given in the world of sensible intuition cannot be considered free because all desire in accordance with this aspect of our existence, being determined by a desire for some object, is only a heteronomous choice governed by the pursuit of some end that I am given. It produces only a hypothetical imperative that whose aims I do not choose. And yet, as subjects we are also prior to, and independent of, experience. When we act on desires that are formed from this standpoint, we truly 'think of ourselves as free, we transfer ourselves into the intelligible world as members and recognise the autonomy of the will. ${ }^{79}$ These provide categorical imperatives that are unconditioned by contingent ends, aiming instead at ends that I give myself. So, both of Kant's epistemological and practical arguments converge to suggest that since a necessary condition of experience is the assumption that we exist outside the representations of sensible intuition, we are therefore free in a very special sense. For Kant 'the idea of freedom is inseparably attached to the concept of autonomy, and to this in turn the universal principle of morality. ${ }^{80}$

It is this notion of autonomy that is crucial to understanding the motivations of liberal ethics. Michael Sandel notes that on the Kantian view the sanctity of individual persons is both moral and foundational, since it 'is grounded in the concept of a subject given prior to its ends, a concept held indispensable to our understanding ourselves as freely choosing, autonomous beings. ${ }^{81}$ What I take to be the central claim of liberal ethics is that we are each conditioned, but part of us is always antecedent to any conditions, and that justice, morality, and freedom depend on our ability to reason in accordance with this aspect of our nature. Since we are capable of reasoning in accordance with an autonomous

\footnotetext{
78 Ibid., 133.

${ }^{79}$ Ibid., 136.

${ }^{80}$ Ibid.s

${ }^{81}$ Sandel, Liberalism and the Limits of Justice, 9.
} 
will, we are each a sovereign subject. As Rawls insisted, we are 'self-originating sources of valid claims. ${ }^{82}$

We can now finally appreciate why liberal ethics takes the moral claims of the individual to be primary. It is due to thoughts both epistemological and practical about what kind of beings we are, and the kind of self-knowledge we are capable of. On the one hand, given the transcendental unity of apperception we must conceive of persons as antecedently individuated subjects that are at least partly prior to, and unencumbered by, their empirical conditions. This suggests that we are free in a very special sense, because we can reason in accordance with a will that is separated from our contingent circumstances. It is our status as subjects of this autonomous will that demands the respect and privileging of the individual. Rawls puts this point forceful when he insisted that each person 'possess an inviolability founded on justice that even the welfare of society as a whole cannot override. ${ }^{83}$ Because we are each autonomous and sovereign subjects, liberalism asserts that the rights secured by individuals can never be 'subject to political bargaining or to the calculus of social interests. ${ }^{84}$ Any social arrangement which fails to respect the distinctness of persons and their prerogative of choice is inherently wrong, because it ignores our status as beings capable of freedom; it would treat persons as objects rather than subjects, as ends rather than means.

Sandel notes that this picture of ethics seems uniquely independent from psychological and teleological assumptions. Reasoning in accordance with an autonomous will does not require that we ascertain generalities about human nature, nor decide on a conception of the good life in respect of virtues or dictates of God. This leave it immune to many problems that plague most political and moral theories. But while it is safe from objection on these fronts, most liberal theories of ethics do require certain things be true about us. That is, they are strongly committed to a view about the nature of the self. Specifically, liberal ethics requires that we are beings given prior to our circumstance, always at a certain distance from them. Conditioned we may be, but part of us must always be prior

\footnotetext{
${ }^{82}$ Rawls, A Theory of Justice, 543.

83 Ibid., 3.

${ }^{84}$ Ibid., 4.
} 
to any conditions. What's more, we must be able to reason in accordance with this aspect of our existence in a meaningful and informative way. This is clearly an epistemological requirement regarding the nature of persons and our capacity for self-knowledge.

\section{3b. LIBERALISM AND PRIVACY}

I think the idea of privacy epitomises a two-century movement toward a kind of 'individualism' in philosophy, the social sciences, and society generally. Expressed most forcefully by the existentialists, liberalism and post-modernism also bear its influence. It marks the transition from a view of the self as a socially-situated entity - dependant on institutional roles for its identity, nature, and reality - to one focused on distinct individuals, with independent natures and realities that transcend the social. Liberalism insists that we can, indeed must, see ourselves as independent of our conditions in this sense. The entire liberal project turns on our ability to reason in accordance with this aspect of our existence, since it is what makes us free and autonomous subjects. I agree with Sandel that though this at first appears to be a psychological assumption, it is actually an epistemological one. It says that I am capable of a kind of self-knowledge that is not conditioned by contingent aspects of my situation; that I am 'a subject whose identity is given independently of the things I have, independently, that is, of my interests and ends and my relations with others. ${ }^{85}$ Liberalism therefore presents a vision of persons that are very robustly independent. It is this aspect of liberal theory that will be most important in the following sections. Whether persons are as individuated as liberalism suggests, and whether privacy can be properly understood in exclusively individual terms, depends largely on the success of this claim.

Before turning to these problems, it is worth acknowledging that, if correct, the liberal view of the self seems fertile ground from which to develop a theory of privacy. If part of us is completely prior to our circumstances then our identity would, to a significant degree, be fixed in advance of our contingent attachments in the world. Privacy seems to follow quite naturally from this view of identity. Assuming persons are so metaphysically

\footnotetext{
${ }^{85}$ Sandel, Liberalism and the Limits of Justice, 55.
} 
independent provides a strong basis for discerning personal information, as well as suggesting that we ought to demonstrate respect for the dignity, autonomy, and worth of persons by respecting their privacy. Isolated and well defined, the liberal subject is a perfect candidate to which we could attach an interest in privacy. If, as liberalism subject, I am an antecedently individuated subject and I can cognise myself in this accordance with this fact, then it is not much of a leap to assume that I would care about this aspect of my existence and want it protected. Establishing a right to privacy, with the aim of ensuring our ability to control who has access to us and our personal information, seems an entirely reasonable consideration on this view of personhood.

Perhaps the clarity with which it appears to define our identity has influenced liberalism's popularity in accounts of privacy. The antecedently individuated subject sits so neatly in contrast to the claims and interests of their community that an account of privacy seems to suggest itself just by the point of this separateness alone. But, as we have said, there is still an epistemological problem that needs to be answered: can we conceive of ourselves in the way liberalism requires? In the following sections, I will suggest that we cannot. Our identities are not as robustly individuated as liberalism would have us believe; privacy, therefore, cannot be understood exclusively in terms of the isolated individual. 


\section{PRIVACY AND THE COMMUNITARIAN SELF}

With the grounds and main commitments of liberalism ascertained, I now turn to the communitarian critique and its import for philosophical thinking about privacy. To do this, I examine arguments by Michael Sandel, Charles Taylor, and Alasdair Macintyre. Together these suggest that the liberal view of the self is only a partial one. Personhood consists not just in our distinctness, but also in essential aspects relating to our roles and relations within the communities we inhabit. I conclude that the liberal notion that personal identity depends essentially on our independence provides a poor basis from which to build an account of what personal information consist in, and why a person has an interest in, or right to, privacy. This conclusion depends on two claims. First, (i) since the liberal subject is so radically unencumbered, it is unclear how personal information becomes 'about' or 'attached to' them. I consider this an issue of possession, arguing that a more complete explanation of the self and its relation to information is necessary to show that the notion of personal information is a meaningful one for an unencumbered subject. Relatedly, (ii) that an isolated subject should have an interest in privacy which precedes connections to any community is far from clear. We care about privacy only because we belong to groups of persons capable of interacting, and particular interactions are imbued with significance by what the information means in those communities. Shared conceptions of personhood, including conceptions of the narrative and character of a human life, play a central role in how we understand ourselves and what constitutes us. These considerations ultimately suggest that social dimensions of privacy are paramount in understanding both its epistemological function and moral status.

\section{4a. Personal Information AND the Problem of Possession}

So far we have considered in detail the kind of subjects liberal ethics take us to be. The claim of most consequence is that we are each constituted, at least in part, by a subject given prior to our circumstance. What's more, liberalism suggests that we can reason in accordance with this aspect of our existence in a way that makes us autonomous, and that this forms the basis of the rights and moral claims that attach to individuals. I said that this amounts to a major epistemological claim about the nature of persons and the kind of self-knowledge we are capable of. For liberal arguments about the sanctity of the 
individual to be convincing, it must be possible for us to gain epistemological access to an understanding of ourselves as unconditioned, autonomous subjects.

Much turns, then, on whether this epistemological requirement can be met. In his book, Liberalism and the Limits of Justice ${ }^{86}$, Sandel considers this question in detail in the context of (and in response to) Rawls' political philosophy. He summarises the view of the self that we have identified as central to liberalism in the following passage:

'The priority of the self over its ends means that I am not merely the passive receptacle of the accumulated aims, attributes, and purposes thrown up by experience, not simply a product of the vagaries of circumstance, but always, irreducibly, an active, willing agent, distinguishable from my surroundings, and capable of choice. To identify any set of characteristics as my aims, ambitions, desires, and so on, is always to imply some subject 'me' standing behind them, and the shape of this 'me' must be given prior to any of the ends or attributes I bear. ${ }^{87}$

This priority of the self as a moral subject is a powerful claim, which underlies Rawls' philosophy and (as we have seen) much of liberal philosophy generally. Kant's arguments for the transcendental unity of apperception demonstrate that liberal ethics is founded on the idea that we always stand at a distance to the circumstances we find ourselves in; that is, from our status as objects of existence in the empirical world. It is this separation of subject and circumstance that constitutes our autonomy and gives us our status as subjects with rights and interests that are deserving of respect. Liberalism prioritises the individual in moral reasoning because of our distinctness. This point, I think, is an appealing and intuitive one. What Kant was surely right about is that we each experience a subjectivity in virtue of our distance and difference from other those things we experience empirically. So far as I am certain that I am me, I stand in contrast to everything else that I am certain is not me. Whatever else we might think a person consists in metaphysically, this seems an indelible property of experience following from the unity of personhood self-

\footnotetext{
${ }^{86}$ Sandel, Liberalism and the Limits of Justice.

${ }^{87}$ Ibid., 19.
} 
consciousness. Privacy fits well with this view of the self as a stable island amidst an ocean of contingent and changing circumstance. A purely empirical treatment of the self, which delivers only the vagaries of successive intuitions, cannot explain the coherence or stability of our personhood though time. That is, it cannot explain our enjoyment of a stable and coherent private life. By showing us that our existence must be separated in this way, liberalism suggests that the bounds of the self are fixed securely in spite of our susceptibility to empirical change.

But the fixedness of our individuality is tempered by our empirical conditioning. The claim that we inhabit a private sphere that is irreducibly prior to our existence as objects of experience is difficult to deny. Yet, this experience of subjectivity is not coterminous with the notion of informational privacy and does little to elucidate its meaning on its own. This is because, as well as the clearly individuated, transcendent subjects that liberalism says we are, we are also partly conditioned by our circumstances. The relationship between myself as a transcendent subject and the totality of information that I consider mine or about me is not a trivial or obvious one. How I possess that information, and what the bounds and limits of privacy are as they relate to my contingent empirical self, are key questions that liberalism has to answer. To provide an account supportive of our more substantive feeling of connection and care to the full breadth of information that we consider, in the everyday sense, personal, requires a connection between our nature as transcendental subject and the information we want protected that is part of our circumstances.

One of the key complexities that the liberal view of the self faces, then, is in dealing with the notion of possession. Sandel notes that since the self, according to liberal ethics, stands always at a distance from its contingent conditions, there is a need to explain how it is related to its desires, interests, and ends. ${ }^{88}$ Though liberalism points out that the self can always be held separate from these, this point immediately raises the problem of how the self is at the same time connected to them. Any theory of the self needs to tell us two things. First, it must tell us what we consist in, and how the bounds of the self are

\footnotetext{
${ }^{88}$ Ibid., 88.
} 
determined. Liberalism seems perfectly able to account for this aspect of our identity. Its insistence that we are at least partly prior to our circumstances secures the bounds of the self outside of its contingent conditions. Equally, though, a theory of the self must explain how we stand in relation to those traits and attributes that we possess. In terms of the liberal subject the issue is how we are to explain what things are mine rather than me, and in what respect they are so.

Sandel argues that 'any theory of the form 'I am $x, y, z$ ', rather than 'I have $x, y, z$ ', (where $x, y$, and $z$ are desires, etc.) collapses the distinction between subject and situation which is necessary to any coherent conception of a particular human subject. ${ }^{89}$ An explanatory concept of possession is therefore an indispensable part of any theory of the self. The concept of possession secures the possibility that we have some of our attributes rather than that we be them. Otherwise, if we were fully constituted by all our attributes, any change in our circumstances, however slight, would change the people we are. If taken literally, given that my situation changes in some way all the time, this would mean that 'my identity would blur indistinguishably into 'my' situation.' 90 Explaining possession is therefore a necessary component of any acceptable theory of the self. Without it, the stability of personal identity gives way and the notion of a subject becomes a meaningless one for beings that persist through time and changing circumstances. Sandel makes this point as it regards desires, wants, and ends, because he is addressing the work of Rawls. His political philosophy is concerned with determining the 'circumstances of justice,' a situation from which we can non-arbitrarily judge the moral status of a society and its arrangement of rights and privileges. I think, however, that the issue of possession for the liberal conception of an isolated self is equally pressing in accounts of privacy. Specifically, it is important to consider how liberal ethics can explain what relates a subject to their personal information. This is essentially the same problem of possession that Sandel raises for other attributes of a self in relation to its circumstance: if it is true that we are each antecedently individuated, and our identity essentially consists in this

\footnotetext{
${ }^{89}$ Ibid., 20.

${ }^{90}$ Ibid.
} 
distinctness, what determines which information relates to us and what does this relation consist in?

Examining Sandel's treatment of the concept of possession helps to bring this problem into focus. First, he notes that the idea of possession is (surprisingly) a distancing, as well as connecting, one:

'In so far as I possess something, I am at once related to it an distanced from it, To say that I possess a certain trait or desire or ambition is to say that I am related to it in a certain way - it is mine rather than yours - and also that I am distanced from it in a certain way - that it is mine rather than me.'91

To possess something is to be specially related to it (it is mine), but this also requires drawing a line of separation between the thing possessed and subject of that possession (it is not me). An explanation of possession therefore requires balancing these two aspects. Sandel notes that without some distinction between the subject and object of possession, 'it becomes impossible to distinguish what is me from what is mine, and we are left with what might be called a radically situated subject. ${ }^{92}$ But a radically situated subject, one whose identity depends on their entire situation - including all contingent, changeable features - fails to capture our identities as persisting and stabile beings. It denies what the liberal self strongly affirms: that we are in some sense a unified being prior to our circumstances. Still, to take a self totally detached from its contingent features is to reference no more than an abstraction.

The phenomenon of privacy brings these two conceptions to a head. On the one hand, subjectivity seems an undeniable feature of our experience. The transcendental unity of apperception is correct in identifying the fact that we each experience the world from a position of distinct consciousness - we feel we are different from those things we experience, and can consider ourselves both objects and subjects of experience. This distinctness suggests that we must think of ourselves as partly prior to our circumstances.

\footnotetext{
${ }^{91}$ Ibid., 55.

${ }^{92}$ Ibid., 21.
} 
As Sandel notes, 'if all the self consisted in were a concatenation of various contingent desires, wants, and ends, there would be no non-arbitrary way, either for the self or for some outside observer, to identify these desires, interests, and ends, as the desires of any particular subject. ${ }^{93}$ At the same time, the totality of what I consider my personal information is heavily conditioned by my empirical existence. Information I take to be about me is, for the most part, variable through time. It also depends at least as much on my status as part of the empirical world as it does on my transcendental existence beyond it.

To see this point, consider a pedestrian example. A presumably uncontroversial piece of my personal information is my address. It is something to which I am intimately connected, and should be a fact that I consider about me. But, this information, while about me, does not constitute an unchanging, essential aspect of my identity. Addresses change, and their meaning and significance for me can both increase and diminish over time. It does not constitute a part of my identity that persists or is never changing. The general interest I have in this information as mine is not explained solely in terms of my experience of being a distinct subject. It depends also on factors about my contingent circumstances, about how I find myself related to things in the world and the information that take to be significant to me in regards to this.

The crucial point is this: the experience of subjectivity (in the Kantian sense) - of being something distinct from and prior to our empirical existence - does not directly entail nor explain the phenomenon of privacy in a range any more expansive than that which the transcendental subject experiences; that is, the immediate results of the transcendental unity of apperception. Privacy is a concept that involves information both related to my status as a subject prior to my circumstances and my status as a subject with an empirical existence that possesses attendant (contingent) facts. Though this aspect of my existence is not as secure or persistent as that which relates only to unchanging aspect of myself that is beyond experience, it nonetheless influences just as much, if not more, that information that I consider about me and which I think worthy of protection.

\footnotetext{
${ }^{93}$ Ibid., 20.
} 
For privacy, the point can be generalised to this: liberal ethics relies on a view of the self that is so radically unencumbered that it is difficult to see how information would become 'about' or 'attached' to it. This makes it very difficult for any kind of self-knowledge that is substantial enough to support reasoning about privacy in a very meaningful sense. We do not need to deny Kant's insight of the necessary unity of apperception, and the degree of prior individuation of persons it suggests, to argue that it nonetheless leaves us with a seriously deficient notion of the whole self. How are we, within the limits of liberal individualism, to decide what information relates to us in the proper way such that it holds some special moral status or interest for us? The relationship between myself as a transcendental subject and the totality of information I want to claim is mine is not a trivial one. The liberal self just doesn't seem to have this connection, at least not without further elucidation.

This problem is, as I have suggested, one about the kind of self-knowledge that we are capable of. Liberalism promotes the rights and interests of the individual because of our supposed status as antecedently individuated, sovereign subjects. This is why accounts of privacy in the liberal tradition cast it as right belonging primarily to individuals. But the kind of abstracted introspection that liberalism requires does not obviously connect with the wider and more grounded concept of personal information. An interest in privacy does not follow immediately from the fact that we experience ourselves as partly delaminated subjects of experience. We also need an account of how we relate to the totality of information we care about, and this will have to be both sensible and super-sensible in scope.

The problem of connecting up the transcendent self and a more standardly human concept of a person is not a new one, nor was it first raised by communitarians. As early as the 1960s, P.F. Strawson made a similar complaint in his famous commentary, The Bounds of Sense:

'Kant fails to overcome the difficulties concerning identity because they cannot be overcome. There is no refuge but incoherence from the question how the connexion is to be made, in the way of identity, 
between the natural being, the man, with a mental history of thoughts, perceptions, and feelings and the supersensible being, with no history at all. ${ }^{94}$

For his part, Strawson did not see this as a problem for Kant's arguments in the Critique. Kant was not there concerned with providing a complete account of personal identity. His point was only that the transcendental unity of apperception is a necessary assumption for any theory of personhood, whatever more substantive view of the nature of persons they might offer. The argument for the necessary unity of apperception was a discovery of necessary, not sufficient, conditions for explaining our self-consciousness. ${ }^{95}$ The liberal account of privacy could perhaps, then, be expanded to include an explanation of why the transcendental subject stands in a special relation to those partly contingent and conditioned facts that we consider constitutive of a person's personal information.

There is, however, a limited scope with which standard liberalism can expand the kind of self-knowledge we are capable of in aid of this task. Consider again the concept of possession. Sandel notes that while liberal ethicists can maintain that the self is a subject of possession, and therefore capable of attachments to things not given prior to experience, there is also an inherent individualism in its commitments which restricts how we might understand this possession. This is because liberalism also requires that we consider selves to be antecedently individuated subjects, standing always at a distance to our interests, desires, and contingent attachments. This puts the self 'beyond the reach of experience,' making it 'invulnerable, [and fixing] its identity once and for all.' 96 The inviolability of the liberal self is empowering for ethics, being the basis of the claim for individual autonomy, but it is also restrictive. Sandel argues that liberalism presents us with 'a self so thoroughly independent' that it 'rules out any conception of the good (or of the bad) bound up with possession in the constitutive sense...[I]t rules out the possibility that common purposes and ends could inspire more or less substantive self-

\footnotetext{
${ }^{94}$ Strawson, The Bounds of Sense: An Essay on Kant's Critique of Pure Reason, 159.

${ }^{95}$ Ibid., 95.

${ }^{96}$ Sandel, Liberalism and the Limits of Justice, 62.
} 
understandings and so define a community in the constitutive sense... ${ }^{97}$ In particular, assuming that selves are so antecedently individuated rules out intersubjective and intrasubjective forms of self-knowledge. Since these 'do not assume that to speak of the self, from a moral point of view, is necessarily and unproblematically to speak of an antecedently individuated self, ${ }^{98}$ they leave open the possibility that defining what we are, and what we consider ours, is a process that depends not just on our status as distinct individuals, but also as participants in a moral community.

If we allow the possibility that self-knowledge encompasses not just our capacity for individual introspection, but also our ability to gain access to shared, communal understandings of the nature of our personhood, the definition of personal information alters considerably. Rather than individuals, we must take the proper locus of privacy concerns to be persons in the context of their communities. Intersubjective conceptions of the self allow that in certain situations, 'the relevant description of the self may embrace more than a single, individual human being. ${ }^{99}$ Such is the case when we identify information about ourselves that is shared with others. We understand the moral pertinence of such facts to consist in their shared meanings; for instance, information about our family, race, or religion. As far as we think such information is ours we also understand it to form part of our identity as members of a community. On the other hand, intrasubjective conceptions of selves 'allow that, for certain purposes, the appropriate description of the moral subject may refer to a plurality of selves within a single, individual human being., ${ }^{100}$ This allows for the possibility of competing identities within a single person, or for forms of occluded self-knowledge, either of which might strengthen or weaken our attachment to particular parts of the totality information we feel attached to at any one time.

The next section will present more detailed arguments for how identity and personal information is shaped in large part by our membership in communities. To conclude here,

\footnotetext{
${ }^{97}$ Ibid.

${ }^{98}$ Ibid.

${ }^{99}$ Ibid., 63.

${ }^{100}$ Ibid.
} 
we can recall the general problem of possession that has been identified. The view of the self that liberalism takes to be central in moral reasoning is far removed from the concept of privacy and personal information in the everyday sense. Our distinctness and antecedent individuation does well to explain how we are distanced from our contingent circumstances, but does not satisfactorily account for how we stand in relation to our circumstances and the information we possess. Reflecting on our transcendental subjectivity provides no self-knowledge of the contingent and variable facts that constitute the information we take to be ours and which we have a special interest in. The relationships between an individual, their community, and their information are not trivial. The individualism inherent in liberal accounts of privacy leaves the connection between a transcendental subject and the totality of their personal information unexplained. To be convincing, they must provide an account of how personal information relates to us and why we care about it.

\section{4b. CHARACTERS, NARRATIVES, AND TRADITIONS}

The major complaint of the previous section was that, though the liberal view of the self can make use of the concept of possession, the contention that the bounds of the self are largely fixed precludes understandings of personhood that hold one's circumstances and community to play a central role in determining who we are and what is ours. While liberalism does well to explain the ways in which we are distinct, to fully capture the essential meaning of privacy, including its moral and metaphysical significance, we need to understand how a person stands in related to the world they inhabit and the information they consider to be about them. We have seen the concept of possession is ill-equipped for this purpose. Without further explanation, the notion of possession leaves the distance between a person and the totality of their personal information unbridged. This explanatory gap persists because the connection between a person and their personal information is not trivial. Those things that we consider ours and those facts that we consider about us are so, I think, in virtue of complex relations between our natures as independent, individuated subjects and our conditioned, contingent circumstances. 
Personal information is 'personal' in a much more fundamental sense than mere ownership. Not only is privacy about protecting things that are about us, it is about protecting aspects of ourselves that are an indelible part of our sense of personal identity. Some philosophers have already adopted a similar stance on the nature of personal information and the role of privacy. Floridi, who we met early on, has argued that we should understand 'the protection of privacy as protection of personal identity. ${ }^{101} \mathrm{He}$ endorses the idea that the relation between an individual and their personal information is one of constitution, arguing that the " "my" in "my data" is not the same "my" as in "my car", it is the same "my" as in "my hand." ${ }^{102}$ His view suggests that what is at stake in privacy debates are not just protections relating to what things and which rights are ours, but also what kind of beings we are and what options are open to us in the future. Floridi appreciates that personal information in determines who we are and what we can become. Privacy is not about establishing the rights an individual has over certain things they possess, nor can it be reduced to other more fundamental rights such as those to property or freedom of expression. ${ }^{103}$ His view of privacy relates the subject to their personal information through both the inherently distancing notion of possession and that of constitution: not only are we conditioned by the empirical facts of our existence, we are partly defined by them.

If we accept that personal information plays a constitutive role in identity and selfknowledge, then we should also find the liberal account of personhood lacking, according to which the bounds of the self are largely fixed prior to experience and circumstance. This rigidity is at odds with the claim that our sense of identity is determined in large part by contingent facts about existence. Once our view of the self is expanded to include aspects beyond just our inherent individuality, the importance of one's community in defining the bounds of the self and its personal information - and hence what we take the value of privacy to consist in - becomes a relevant area of enquiry. Deciding what information we take to be about us and, therefore, what information we think we have a special interest in protecting, is a difficult task for a person whose bounds are limited in

\footnotetext{
${ }^{101}$ Floridi, “On Human Dignity as a Foundation for the Right to Privacy,” 307.

102 Ibid., 308.

103 Ibid.
} 
the way the liberalism would have us believe. For a self whose existence is given not just through its distinctness from other things and other selves, but also from its relatedness to them, obtaining self-knowledge is a much more involved, less easily defined task. On such an account of personhood, determining who we are and what is ours is a more complex, less strictly personal thing.

Communitarian philosophers have developed various arguments for the importance of community, circumstance, and history in determining a person's identity and the kind of self-knowledge that is available to them. In the context of privacy, especially regarding the problem of defining personal information, I think three broad concepts are worth considering. First is the notion of character. We will see that Sandel develops this idea in terms of attachments to different communities, arguing that it is an essential part of our moral commitments. Second is the claim for the prominence of narrative - particularly shared narrative - in determining how we see and communicate the meaning of our lives and the values to which we feel committed. Charles Taylor develops this claim in terms of the indispensable 'orientation' that a community provides the individual. This also includes the immediate role of language in facilitating self-knowledge. Finally, there is the importance of tradition. Developed most fully in the work of Alasdair MacIntyre, being part of a tradition requires seeing oneself as part of a shared historical group, with associated values, meanings, and understandings. This, he claims, is a necessary part of developing a full sense identity. I do not expect these arguments to be exhaustive. Most likely there are many other ways that community and circumstance determine an individual's identity in general, as well as the importance attaching to privacy specifically. Each of these points does, however, suggest that the role of privacy cannot be fully explained in purely in individualistic terms. Our sense of identity depends significantly on the communities we inhabit and the resources they provide us for selfknowledge; so too does our want of privacy and the meaning we attach to information we consider to be about us. Any satisfactory account of privacy had better acknowledge this general feature. In considering the interests an individual has in respect of their personal information, privacy brings focus to these relations. Arguing for the importance of one's circumstance in defining who we consider ourselves to be, and in-turn what information we consider to be ours, is the task of this section. 
To begin, we will take Sandel's notion of character. His argument is a direct criticism of the liberal's claim that persons are, essentially, independent selves, always partly apart from and prior to their particular ends and circumstances. Sandel believes this view of the self to be motivated by a picture of the world as ungoverned by a purposive order, such that 'the principles of justice [are] open to human construction and conceptions of the good to individual choice. ${ }^{, 104}$ We have seen already that a major tenant of standard liberal ethics is the claim that we are autonomous rational agents. Most often, this is equated with a particular kind of detachment that persons are capable of: Because we each stand at a distance from our circumstances and commitments, we can reason in accordance with a universal rational law that is independent of those contingent aspects of our existence. Empowering though this view of human agency may seem, Sandel's work forces us to seriously consider the ramifications of endorsing an account of personhood according to which we are so radically independent and ungoverned by external principles. In particular, he is concerned to show that the liberal self would be capable of only a limited moral life.

Before making this point, Sandel first identifies two central features of the self that appear difficult to reconcile: its distinctness and its unity. Any two people are each certainly distinct in so far as they are not one-and-the-same, but an equally pertinent point is that each is, at the level of being an individual, a unified whole. I argued earlier that while liberalism can explain perfectly well how persons are distinct, it struggles to account for our connectedness to those contingent aspects of existence. Though it may be possible to consider the distinctness and unity of the self only in turn, as though both were independent of the other, Sandel thinks it 'difficult in practice to observe the distinction between these two features of the self without also remarking their internal connection. ${ }^{105}$ Even when our theoretical focus is to discern the bounds of the self and its metaphysical limits, we find 'occasion to seek a principle of unity and to anticipate a theory of community that might provide it. ${ }^{106}$ Persons cannot be considered only in

\footnotetext{
${ }^{104}$ Sandel, Liberalism and the Limits of Justice, 175.

105 Ibid., 134.

${ }^{106}$ Ibid.
} 
isolation - practicality demands that any theory of selfhood explain also the inherent unity of selves and the connections that are maintained between them. This means that community, in the everyday sense, is an explanatorily necessary component of any account of personhood.

The liberal view of the self is admittedly emboldening. The claim that human agency is prior to, and independent from, empirical constraints secures a satisfyingly universal degree of individual autonomy. But Sandel thinks this vision flawed, both as an account of human nature and moral experience. The distance liberal theory creates between the subject and its circumstance is to him both a source of great power and its most significant limitation. Sandel argues that humanness consists in much more than our status as distinct individuals: understanding who we really are and what values matter to us involves, amongst other things, aspects of our existence that are not determined before or beyond experience. It is best to appreciate this point, I think, as pertaining to the 'richness' of human life - especially in contrast to the limited sources of meaning that are available to the isolated, liberal self. As Sandel puts it, to imagine a person so dethatched as the liberal self 'is not to conceive an ideally free and rational agent, but to imagine a person wholly without character, without moral depth.' ${ }^{107}$ The liberal self 'is incapable of selfknowledge in any morally serious sense,' because where 'the self is unencumbered and essentially dispossessed, no person is left for reflection to reflect upon. ${ }^{\text {'108 }}$

Sandel's notion of character draws attention those attachments and commitments which, though not a priori or necessary, are nonetheless indispensable aspects of our moral experience. Liberalism insists that we view ourselves as independent selves, independent in the sense that we always stand apart from our particular aims and attachments. This assures the continuity of the self by giving it the power to disassociate from those aspects of experience that are changeable and happenchance. But Sandel's central claim is that we cannot regard ourselves as independent in this way without losing sight of those attachments and loyalties which are inseparable from understanding ourselves as the

\footnotetext{
107 Ibid., 179.

${ }^{108}$ Ibid.
} 
particular persons we are. To form a robust sense of identity requires, amongst other things, to be attached to values and understandings that one shares with others. I am not only me as an individual, I am also me as part of this family, state, religion, history, and much more. Taken together, such attachments are not just a sum of contingencies - they are enduring and defining aspects of the person that I am. Sandel remarks that for 'persons encumbered in part by a history they share with others...knowing oneself is a more complicated thing. It is also a less strictly private thing.' ${ }^{109}$ This result is of key importance to our examination of privacy. Recalling specifically the problem of personal information, I said that because of its narrow focus on individuals, liberalism struggles to explain how we are related to our information and why we think it worthy of protection. But communitarians extend the horizon of the genuine self-knowledge to include attachments, commitments, and understandings that are not private but shared. In doing so they provide, I think, a much richer and more convincing account of what information counts as personal and why so.

Understanding what information is mine, and hence what information is the subject of my privacy concern, depends not only on my capacity for critical self reflection. It depends too on those commitments and attachments I share with others to maintain different levels of intimacy and openness. Consider again James Rachels' argument that the value of privacy consists primarily in allowing us to maintain different kinds of relationships with different people. ${ }^{110}$ This is certainly a common motivation for informational privacy, if not perhaps the most basic. But sharing or withholding information from certain groups is not a meaningful act for the individual alone. Rather, it is a response to the shared value placed on certain kinds of personal information by the communities we are part of. So far as we are members of different communities, so too do we have different expectations about what information should and should not be available to others in different groups. Things about me that I consider proper for my family to know might, for instance, be highly private in the context of other communities I am also part of. Knowing you are ill might be something you feel your family has a right

\footnotetext{
109 Ibid., 181.

${ }^{110}$ See page 15 .
} 
to know and to which no reasonable expectation of privacy attaches. Yet the less intimate a relationship is generally the more likely we are to feel that information ought to be disclosed only at a person's discretion. One way to explain this variance is to look for the value that different communities place on certain types of facts. We are not free to choose the meaning and value of personal information by ourselves. The value of privacy, its extension and its limits, are set not by the sovereign individual, but in response to the shared meanings and understandings that a person's various communities believe certain kinds of information to have. Judging who I am and what information is mine is not, therefore, an exclusively personal matter. As Sandel concludes:

'Once the bounds of the self are no longer fixed, individuated in advance and given prior to experience, there is no saying in principle what sorts of experience could shape or reshape them, no guarantee that only 'private' and never 'public' events could conceivably be decisive. $^{111}$

How the private and public interact is also a central feature of the work of Charles Taylor. He too finds the rise of modern individualism troubling, insisting that the Kantianinspired view of independent selves provides only a shallow account of human experience. Where Sandel talks about the importance of communities, Taylor speaks of frameworks. Both, however, are concerned with the strong ties and commitments that partly define a person's identity. For Taylor, to say that I see myself as a Christian or an atheist, or as a New Zealander or an Australian, is not just to feel strongly attached or committed to this or that view of background; it is to relate the frameworks with which I navigate my life and by which I judge the value and meaning of the good, admirable, and valuable. ${ }^{112}$ Though no particular framework may be universal, to lack any framework would leave an individual radically uncertain of where they stand, since they would 'lack a frame of horizon within which things can take on a stable significance. ${ }^{113}$

\footnotetext{
111 Ibid., 183.

112 Charles Taylor, Sources of the Self: The Making of the Modern Identity (Cambridge, Mass.: Harvard University Press, 1989), 27.

113 Ibid.
} 
Taylor believes frameworks to provide a kind of essential orientation. A proper sense of identity emerges only when one feels committed to a set of frameworks that they share with others, which orientate their lives by securing values and meanings that are unavailable for the isolated individual. To be without such commitments, he thinks, leaves an individual 'at sea,' since they 'wouldn't know anymore what, for an important range of questions, what the significance of things was for them. ${ }^{114}$ Knowing who one is requires knowing where one stands on questions of value of worthiness. It is frameworks that we use to justify our answers for these kinds of questions and which secure us a robust and enduring sense of identity.

One of the most interesting formulations of this point is how our sense of self relates to the mastery of language. In Wittgensteinian fashion, he notes that a language only exists and is maintained within a language community. Similarly, Taylor argues that 'one is a self only among other selves. A self can never be described without reference to those who surround it.' 115 This is because the question of who I am finds its original sense in the interchange of speakers. We define who we are by speaking from a particular perspective, by having answers that exhibit a sense of orientation we employ for questions of value and meaning. This much agrees with Sandel's focus on the importance of community. Taylor makes the further point, however, that being able to do this requires initiation in a language community. To be a self requires knowing where one stands; to be able to tell from where one is talking and to whom. A self exists, therefore, only within what Taylor calls a 'web of locution.' It is this dimension of identity-definition that Taylor thinks is the original situation out of which entire problem of identity arises. Narrative, then, is key to Taylor's account selfhood.

A robust sense of personal identity requires a person be able to engage in questions of value and meaning with interlocutors, real or imaginary; to make sense of their life in terms of a story that references meanings outside their own existence and that are also equally meaningful and legitimate to others. Our capacity for building a narrative that

\footnotetext{
114 Ibid.

115 Ibid., 37.
} 
guides self-understanding depends not only on our status as isolated individuals. It is informed and shaped by the orientation we receive from those communities which we are part of. After all, a language sustaining shared values and meanings is only possible in the context of a language community. In, The World of Perception, Merleau-Ponty made this point poetically, arguing that 'the adult will discover in his own life what his culture, education, books and tradition have taught him to find. ${ }^{116}$ Taylor uses Kant's own terminology when he describes interlocution (or its possibility) as a transcendental condition of selfhood. ${ }^{117}$ This claim shows how strongly he believes one cannot be a self on one's own. On the one hand, conversation partners provide an indispensable method for achieving self-definition: they provide us with interpretive frameworks to guide action and make sense of our lives through the construction of narratives. At the same time, interlocutors maintain the languages which we use for self-understanding. ${ }^{118}$

We can take two points from Taylor's work as informative here. First, talk of privacy, like language, is meaningful only in the context of a self among other selves. Concern about keeping things about me unknown seems reasonable only if there is someone (or something) besides me which has the capacity to know. Whether a single individual completely free of this fear could have a working concept of privacy is at best doubtful. Just as a language is only established and maintained within a community of speakers, so too expectations of privacy can only be consequential within a community of interlocutors capable of transmitting and knowing information about each other. We need not take this point as a logical certainty. It is enough to point out that an account of privacy will be motivated, at least initially, by the concerns of individuals that are members of real, extant communities where knowledge about them can be shared.

More deeply, Taylor's argument for the central role of community in sustaining meaning suggests a more general point about the originality of personal information and the scope of our personal dominion over its meaning. Though I may think some fact to be true about

\footnotetext{
116 Maurice Merleau-Ponty, The World of Perception, trans. Oliver Davis, Routledge (New York, NY: Routledge, 1948), 67.

117 Taylor, Sources of the Self: The Making of the Modern Identity, 39.

118 Ibid., 36.
} 
me, I cannot sustain its cogency or meaning on my own. Many things about us that we think form the core of our identity - such as our religion, nationality, or race - depend on meanings and understandings that can only be sustained through agreement with others. I may call myself a New Zealander, but the meaning and significance of this term is not all in my control: though it is mine, it's interpretation requires a common language of meanings that I share with others. Even very basic facts about our identity depends on the kinds of self-knowledge that interaction with our fellow interlocutors provide. So far as privacy tells us what kinds of information are personal and ought to be protected, it only does so in the context of shared narratives that themselves give content and meaning to that information and, most fundamentally, establish our sense of personal identity.

We have talked so far of narratives in only a very abstract sense. This leaves open the worry that narratives are too variable and open to revision to secure any lasting sense of identity. While liberalism secures the bounds of the self too rigidly, narratives might seem too optional and happenchance to secure anything at all. Clearly not just any kind of narrative will do. Alasdair MacIntyre notes that 'what is crucial to human beings as characters in enacted narratives is that, possessing only the resources of psychological continuity, we have to be able to respond to the imputation of strict identity. ${ }^{119}$ Finding oneself in a sea of enacted narratives, each open to change and revision, seems a daunting task.

According to MacIntyre, the demands of sustained identity can met by appreciating the role of tradition in determining personal identity. The narratives we employ for self understanding must, on his account, be rooted in a history and be supported by a lasting cultural practice. ${ }^{120}$ Like Taylor, he thinks humans are essentially story-telling animals. Despite much effort, we lack a coherent, rationally defensible statement of liberal individualism because, in trying to picture the isolated subject, liberalism ignores the central role of historical narrative in forming the identity of a person:

\footnotetext{
${ }^{119}$ Alasdair MacIntyre, After Virtue (Notre Dame, IN.: University of Notre Dame Press, 1981), 217.

${ }^{120}$ MacIntyre, After Virtue.
} 
'Just as history is not a sequence of actions, but the concept of an action is that of a moment in an actual or possible history abstracted for some purpose from that history, so the characters in a history are not a collection of persons, but the concept of a person is that of a character abstracted from history. ${ }^{121}$

A narrative must have historicity if it is to provide the right kind of unified meaning to a life. Of course, my particular history is unique: I am the subject of a history in so far as it is mine and no one else's. ${ }^{122}$ At the same time, without a narrative rooted in a history that is given to me I cannot make sense of my life. What I am is, therefore, 'in key part what I inherit...I find myself part of a history and that is generally to say, whether I recognise it or not, part of a tradition., ${ }^{123}$

That our personal identity is determined in large part by narratives we inherit from a shared history is a powerful explanatory device for understanding privacy. In particular, it explains why privacy expectations vary so widely between different cultures and time periods. Once we accept that the bounds of the self are not fixed, the only way to decide what information is personal and worthy of protection is to study those narratives and traditions that an individual and their community employs to determine the identity and the unity of a person's life. These narratives do not just get at some more basic unit of identity - they are the conditions of identity itself.

The importance of tradition helps explain why so much variance is observed between the privacy practices of different cultures. Much research shows that privacy-related behaviour is culturally sensitive today, even between highly developed countries that share similar modern histories. ${ }^{124}$ Or, consider religious practices that hold parts of the

\footnotetext{
121 Ibid.

${ }^{122}$ Ibid.

123 Ibid.

124 See, for instance: Robert Thomson, Masaki Yuki, and Naoya Ito, "A Socio-Ecological Approach to National Differences in Online Privacy Concern: The Role of Relational Mobility and Trust,” Computers in Human Behavior 51, no. PA (2015): 285-92, doi:10.1016/j.chb.2015.04.068; Philip J. Reed, Emma S. Spiro, and Carter T. Butts, “Thumbs up for Privacy?: Differences in Online Self-Disclosure Behavior across National Cultures,” Social Science
} 
female body to be highly private, which in other cultures have an expectation of public display. The use of the niqab to cover the face, for instance, is seen by many wearers to protect their essential privacy and dignity, ${ }^{125}$ while no such violation is threatened by the face being shown in other cultures. Similarly, the role of tradition in personal identity explains why privacy practices have altered so much throughout history within a single cultural group. We need only look at Victorian's excessive prudishness to see that our expectations about what is properly private and public has changed much over past centuries. What we choose to disclose, that is, what we see as belonging to the private or public domains, is not fixed by the metaphysics of an a prori concept of selfhood; it is determined by the narratives we employ for self understanding from a shared tradition.

Research 59 (2016): 155-70, doi:10.1016/j.ssresearch.2016.04.022; Michael M. Harris, Greet Van Hoye, and Filip Lievens, "Privacy and Attitudes Towards Internet-Based Selection Systems: A Cross-Cultural Comparison," International Journal of Selection and Assessment 11, no. 2-3 (2003): 230-36, doi:10.1111/1468-2389.00246.

${ }^{125}$ Reed, Spiro, and Butts, “Thumbs up for Privacy?: Differences in Online Self-Disclosure Behavior across National Cultures.” 


\section{CONCLUSION}

Though communitarian theories became popular only at the end of the last century, similar themes have a much longer history in continental philosophy. Heidegger famously claimed that a person's existence, or Dasein, is essentially that of a 'being-in-the-world.' By this he meant that a person's being (that is, existing) is inseparable from their world, since existing in a world is the basic ontological state of human existence. On the relationship between person and object, he wrote:

'When Dasein directs itself towards something and grasps it, it does not somehow first get out of an inner sphere in which it has been proximally encapsulated, but its primary kind of Being is such that it is always 'outside' alongside entities which it encounters and which belong to a world already discovered. ${ }^{126}$

The rejection of an 'inner sphere' is an apt characterisation of the communitarian position in general. Empowering as the liberal view of the self may be, we cannot consider ourselves as fully independent from our circumstances without great cost to the loyalties, commitments, and values that we share with others. Any account of privacy must explain what information is personal and why so. But self-knowledge is a much less personal thing than liberalism suggests. To settle questions of personal identity we must appreciate our nature as beings partly independent, but also indispensably connected. Appreciating our situatedness, as beings who find meaning in a world we inhabit with others, requires us to search for guiding frameworks and principles that are rooted in our connectedness. Marx objected that 'none of the so-called rights of man go beyond egotistic man, as he is in civil society, namely an isolated monad,... withdrawn behind his private interests and whims and separated from the community.' 127 To understand the meaning and value of privacy, we must look to the bonds of individuals united in dialogue and shared understandings of personhood, for it is only there that we find the need to be let alone.

\footnotetext{
${ }^{126}$ Martin Heiddiger, Being and Time (New York, NY: Harper Collins, 2008), 323.

${ }^{127}$ Karl Marx, “On The Jewish Question,” in Karl Marx: Selected Writings, ed. David McLellan, 2nd ed. (Oxford: Oxford University Press, 2000), 51.
} 


\section{BIBLIOGRAPHY}

DeCew, Judith Wagner. "The Feminist Critique of Privacy.” In Social Dimsensions of Privacy, edited by Beate Roessler and Dorota Mokrosinska, 85-103. Cambridge: Cambridge University Press, 2015.

Diggelmann, Oliver, and Maria Nicole Cleis. "How the Right to Privacy Became a Human Right.” Human Rights Law Review 14, no. 3 (2014): 441-58. doi:10.1093/hrlr/ngu014.

Emerson, Thomas I. The System of Freedom of Expression. New York, NY: Random House, 1970.

Etzioni, Amitai. Privacy in a Cybver Age: Policy and Practice. New York, NY: Palgrave Macmillan, 2015.

- The Limits of Privacy. New York, NY: Basic Books, 2008.

Floridi, Luciano. "Four Challenges for a Theory of Informational Privacy.” Ethics and Information Technology 8, no. 3 (2006): 109-19. doi:10.1007/s10676-006-9121-3.

—. "On Human Dignity as a Foundation for the Right to Privacy.” Philosophy and Technology 29, no. 4 (2016): 307-12. doi:10.1007/s13347-016-0220-8.

- "The Ontological Interpretation of Informational Privacy." Ethics and Information Technology 7, no. 4 (2005): 185-200. doi:10.1007/s10676-006-0001-7. Harris, Michael M., Greet Van Hoye, and Filip Lievens. "Privacy and Attitudes Towards Internet-Based Selection Systems: A Cross-Cultural Comparison.” International Journal of Selection and Assessment 11, no. 2-3 (2003): 230-36. doi:10.1111/14682389.00246.

Heiddiger, Martin. Being and Time. New York, NY: Harper Collins, 2008.

Hixson, Richard F. Privacy in Public Society: Human Rights in Conflict. New York, NY: Oxford University Press, 1987.

Johnston, James Scott. Kant's Philosophy: A Study for Educators. New York, NY: Bloomsbury, 2013.

Johson, Deborah G, and Priscilla M Regan, eds. Transparency and Surveillance as Sociotechnical Accountability: A House of Mirrors. New York, NY: Routledge, 2014.

Kant, Immanuel. The Critique of Pure Reason. Translated by Paul Guyer and Allen W 
Wood. Cambridge: Cambridge University Press, 1998.

- The Moral Law: Groundwork for the Metaphysics of Morals. Translated by H J Paton. London: Routledge, 2005.

MacIntyre, Alasdair. After Virtue. Notre Dame, IN.: University of Notre Dame Press, 1981.

MacKinnon, Catharine. Toward a Feminist Theory of the State. Cambridge, MA.: Harvard University Press, 1989.

Marmor, Andrei. "What Is the Right to Privacy?” Philosophy \& Public Affairs 43, no. 1 (2015): 3-26.

Marx, Karl. “On The Jewish Question.” In Karl Marx: Selected Writings, edited by David McLellan, 2nd ed., 46-70. Oxford: Oxford University Press, 2000.

Merleau-Ponty, Maurice. The World of Perception. Translated by Oliver Davis. Routledge. New York, NY: Routledge, 1948.

Mohanty, Hrushikesha. “Big Data: An Introduction.” In Big Data, edited by Hrushikesha Mohanty, Prachet Bhuyan, and Deepak Chenthati, Vol. 11. Studies in Big Data. New Delhi: Springer India, 2015. doi:10.1007/978-81-322-2494-5.

Rachels, J. "Why Privacy Is Important.” Philosophy \& Public Affairs 4, no. 4 (1975): 323-33. https://www.jstor.org/stable/2265077.

Rand, Ayn. The Fountainhead. Indeanapolis, IN: Bobbs-Merrill, 1943.

Rawls, John. A Theory of Justice. Oxford: Clarendon Press, 1972.

Reed, Philip J., Emma S. Spiro, and Carter T. Butts. "Thumbs up for Privacy?: Differences in Online Self-Disclosure Behavior across National Cultures.” Social Science Research 59 (2016): 155-70. doi:10.1016/j.ssresearch.2016.04.022.

Regan, Priscilla M. Legislating Privacy: Technology, Social Values, and Public Policy. Reissue Ed. Chapel Hill, NC: The University of North Carolina Press, 1995.

_ . "Privacy and the Common Good: Revisited." In Social Dimsensions of Privacy, edited by Beate Roessler and Dorota Mokrosinska, 50-70. Cambridge: Cambridge University Press, 2015.

Reiman, Jeffrey H. “Privacy, Intimacy, and Personhood.” Philosophy \& Public Affairs 6, no. 1 (1976): 26-44. http://ezproxy.library.nyu.edu:2105/stable/2265060.

Richardson, Janice. “The Changing Meaning of Privacy, Identity and Contemporary Feminist Philosophy.” Minds and Machines 21, no. 4 (2011): 517-32. 
doi:10.1007/s11023-011-9257-8.

Sandel, Michael J. Liberalism and the Limits of Justice. Cambridge: Cambridge University Press, 1998.

Scanlon, Thomas. “Thompson on Privacy.” Philosophy \& Public Affairs 4, no. 4 (1975): 315-22.

Solove, Daniel. Understanding Privacy. Cambridge, MA.: Harvard University Press, 2008.

Solove, Daniel J. “The Meaning and Value of Privacy.” In Social Dimsensions of Privacy, edited by Beate Roessler and Dorota Mokrosinska. Cambridge: Cambridge University Press, 2015.

Strawson, Peter F. The Bounds of Sense: An Essay on Kant's Critique of Pure Reason. New York, NY: Routledge, 1966.

Taylor, Charles. Sources of the Self: The Making of the Modern Identity. Cambridge, Mass.: Harvard University Press, 1989.

Thompson, Judith Jarvis. "The Right to Privacy.” Philosophy \& Public Affairs 4, no. 4 (1975): 295-314.

Thomson, Robert, Masaki Yuki, and Naoya Ito. “A Socio-Ecological Approach to National Differences in Online Privacy Concern: The Role of Relational Mobility and Trust." Computers in Human Behavior 51, no. PA (2015): 285-92. doi:10.1016/j.chb.2015.04.068.

Vermaas, Pieter, Peter Kroes, Ibo van de Poel, Maarten Franssen, and Wybo Houkes. A Philosophy of Technology: From Technical Artefacts to Sociotechnical Systems. Synthesis Lectures on Engineers, Technology and Society. Vol. 6, 2011. doi:10.2200/S00321ED1V01Y201012ETS014.

Warren, Samuel D, and Louis D Brandeis. “The Right to Privacy.” Harvard Law Review 4, no. 5 (1890): 193-220. doi:10.1525/sp.2007.54.1.23.

Westin, Alan. Privacy and Freedom. New York, NY: Atheneum, 1967. 